\title{
Preconception care: nutritional risks and interventions
}

\author{
Sohni V Dean, Zohra S Lassi, Ayesha M Imam, Zulfiqar A Bhutta*
}

\begin{abstract}
Introduction: There is increasingly a double burden of under-nutrition and obesity in women of reproductive age. Preconception underweight or overweight, short stature and micronutrient deficiencies all contribute to excess maternal and fetal complications during pregnancy.

Methods: A systematic review and meta-analysis of the evidence was conducted to ascertain the possible impact of preconception care for adolescents, women and couples of reproductive age on maternal, newborn and child health $(\mathrm{MNCH})$ outcomes. A comprehensive strategy was used to search electronic reference libraries, and both observational and clinical controlled trials were included. Cross-referencing and a separate search strategy for each preconception risk and intervention ensured wider study capture.
\end{abstract}

Results: Maternal pre-pregnancy weight is a significant factor in the preconception period with underweight contributing to a $32 \%$ higher risk of preterm birth, and obesity more than doubling the risk for preeclampsia, gestational diabetes. Overweight women are more likely to undergo a Cesarean delivery, and their newborns have higher chances of being born with a neural tube or congenital heart defect. Among nutrition-specific interventions, preconception folic acid supplementation has the strongest evidence of effect, preventing $69 \%$ of recurrent neural tube defects. Multiple micronutrient supplementation shows promise to reduce the rates of congenital anomalies and risk of preeclampsia. Although over $40 \%$ of women worldwide are anemic in the preconception period, only one study has shown a risk for low birth weight.

Conclusion: All women, but especially those who become pregnant in adolescence or have closely-spaced pregnancies (inter-pregnancy interval less than six months), require nutritional assessment and appropriate intervention in the preconception period with an emphasis on optimizing maternal body mass index and micronutrient reserves. Increasing coverage of nutrition-specific and nutrition-sensitive strategies (such as food fortification; integration of nutrition initiatives with other maternal and child health interventions; and community based platforms) is necessary among adolescent girls and women of reproductive age. The effectiveness of interventions will need to be simultaneously monitored, and form the basis for the development of improved delivery strategies and new nutritional interventions.

\section{Introduction}

Nutritional status is an important aspect of health and wellness before and during pregnancy. Under nutrition in women contributes to $20 \%$ of maternal deaths, and is a significant risk factor for stillbirths, preterm births, small for gestational age and low birth weight babies [1-7], yet in most countries $10-20 \%$ of women are underweight [8]. Maternal short stature heightens the risk for obstructed labor, obstetric fistula and maternal mortality, as well as

\footnotetext{
*Correspondence: zulfiqar.bhutta@aku.edu

Division of Women and Child Health, Aga Khan University Karachi, Pakistan
}

birth asphyxia leading to neonatal death, and is often the result of girls being stunted since childhood [9]. Prepregnancy overweight and obesity has been linked to two of the foremost causes of maternal mortality $[10,11]$ hypertensive disorders of pregnancy [12-15] and gestational diabetes mellitus (GDM) [16,17]- as well as an entire spectrum of adverse pregnancy outcomes [1-7], including poor lactation practices $[18,19]$, obstetric anesthesia-related complications [20], prolonged gestation [21,22], maternal infectious morbidity [23] and decreased success with trial of labor [24-27]. Maternal obesity is a cause for stillbirths, fetal and neonatal death 
$[3,28-31]$, and moreover, perpetuates the obesity epidemic since children of obese women are more likely to be obese themselves [17,32-36].

In addition to weight, micronutrient status is also linked to pregnancy outcomes. The recent Cochrane review [37] found a strong protective effect (RR 0.28, 95\% CI 0.15-0.52) of folic acid on recurrent neural tube defects (NTDs). Other meta-analyses of randomized and observational studies showed a reduction in recurrence risk of 69 to $100 \%$ [38] and a reduction in occurrence risk of 42 [39] to $62 \%$ [40], yet less than half of all women regularly consume folic acid before conception [41]. Despite research evidence linking iron deficiency with maternal mortality, around $40 \%$ of women are anemic globally [9]. Other micronutrients such as zinc and calcium have been found to improve maternal and newborn outcomes when supplementation is provided during pregnancy- it seems likely that ensuring adequate intake of these micronutrients earlier, which is during the preconception period, would be of added benefit for undernourished girls and women and in the case of unplanned pregnancies. Folic acid, B vitamins and zinc have been shown to affect early fetal development, even before women realize they are pregnant. Micronutrient supplementation or fortification is currently being used as strategies to improve nutrition even in resource-poor settings since many girls and women are chronically undernourished [42].

There is a dearth of intervention trials to address undernutrition or obesity in women of reproductive age. Weight and micronutrient status during pregnancy is influenced by a number of factors such as food insecurity and birth spacing that require broad interventions, hence the aim should to achieve and sustain optimal nutritional intake and weight before pregnancy. In addition, even for women who are overweight or obese, losing weight is not recommended during gestation and therefore weight and nutritional status should be reviewed between pregnancies. Nutritional risks and interventions are an important component of preconception care, defined for the purpose of this review as "any intervention provided to women and couples of childbearing age, regardless of pregnancy status or desire, before pregnancy, to improve health outcomes for women, newborns and children" (Detailed discussion of the importance and scope of preconception care is given elsewhere) [43].

This paper presents the findings of a systematic review that was undertaken to consolidate the evidence for nutritional risks before pregnancy, and ascertain the effectiveness of providing interventions during the preconception period (versus periconception or prenatal) on maternal, newborn and child health $(\mathrm{MNCH})$ outcomes. The first section discusses pre-pregnancy weight, which is followed by diet and exercise as interventions to achieve and maintain optimal weight. This is followed by the sections on folic acid, multivitamin and iron supplementation in the preconception period. The review also looks beyond efficacy of an intervention to studies that examined impact of strategies used to increase uptake.

\section{Methods}

We systematically reviewed all literature published up to 2011 to identify studies describing the effectiveness of preconception (period before pregnancy and between pregnancies) nutritional risks and interventions and their impact on maternal, newborn and child health $(\mathrm{MNCH})$ outcomes. Electronic databases such as PubMed, Cochrane Libraries, Embase, and WHO Regional Databases were searched to identify the studies. We included systematic reviews, experimental and observational studies. Papers were also identified by hand searching references from included studies. No language or date restrictions were applied in the search. The findings were presented at international meeting $[44,45]$ and shared with professionals in the relevant fields of maternal and child health, following which results were updated based on current searches (through end of 2012) and expert opinion. Studies were included if they reported the nutritional risks and interventions for $\mathrm{MNCH}$ outcomes. Methodology is described in detail elsewhere [43].

For the studies that met the final inclusion criteria, two review authors abstracted data describing study identifiers and context, study design, intervention specifics and outcome effects into a standardized abstraction sheets. The quality of experimental studies were assessed using Cochrane criteria [46], whereas STROBE guidelines were used to assess the quality of observational studies [47]. We conducted meta-analyses for individual studies and pooled statistics was reported as the odds ratio (OR) and relative risk (RR) between the experimental and control groups with $95 \%$ confidence intervals (CI). Mantel-Haenszel pooled RR and corresponding 95\% CI were reported or the Der SimonianLaird pooled RR and corresponding 95\% CI where there was an unexplained heterogeneity. All analyses were conducted using the software Review Manager 5.1 [48]. Heterogeneity was quantified by $\mathrm{Chi}^{2}$ and $\mathrm{I}^{2}$, in situations of high heterogeneity, causes were explored and random effect models were used.

\section{Results}

The review identified 2034 papers from search in all databases. After the initial title and abstract screening, 198 full texts were reviewed to identify papers which met the inclusion criteria and had the outcomes of our interest. One hundred and forty six studies were finally selected for abstraction and analysis (Figure 1). Information related to 


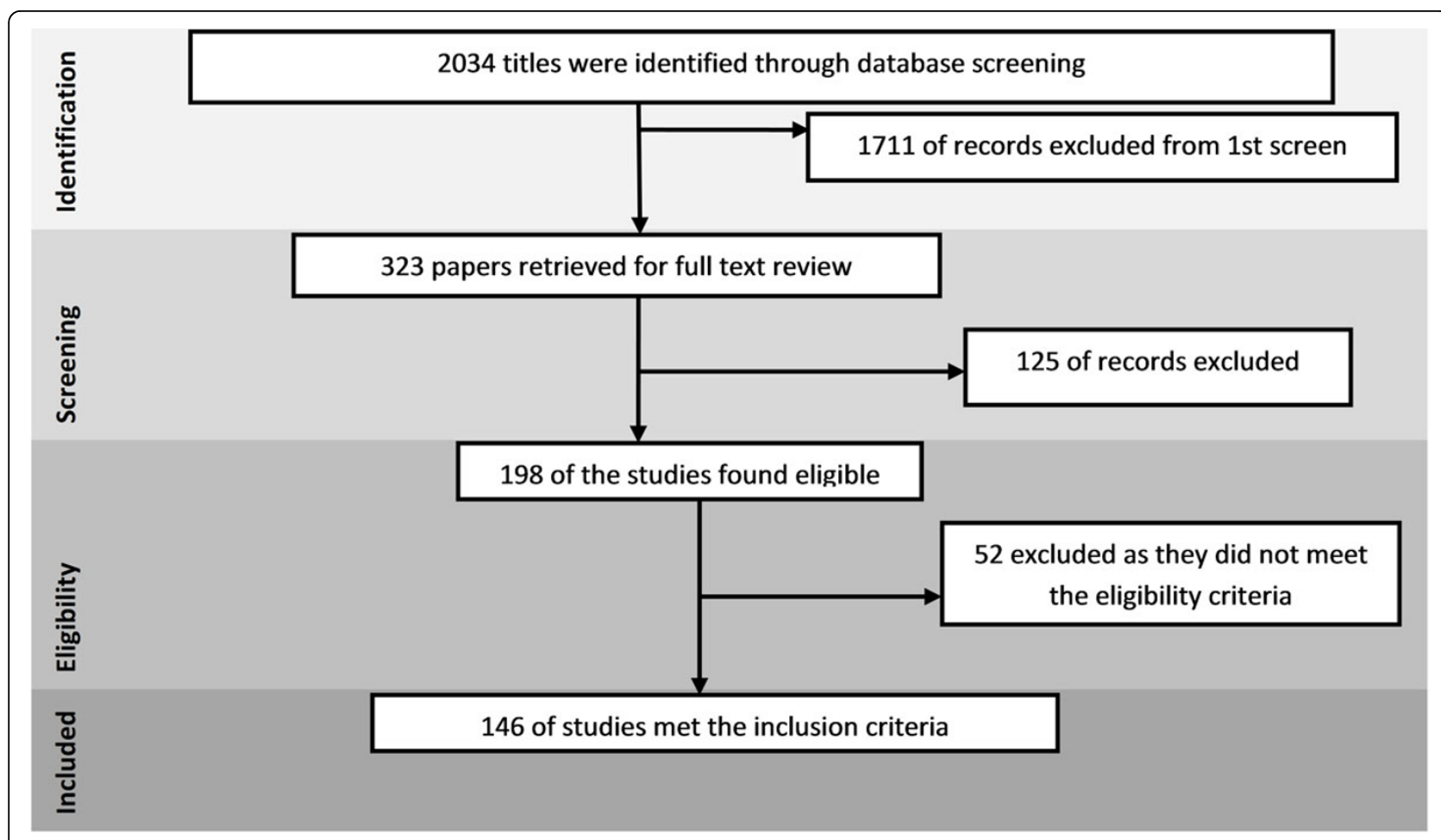

Figure 1 Search flow diagram

each included study can be found on the following link: https://globalmotherchildresearch.tghn.org/site_media/ media/articles/Preconception_Report.pdf

\section{Nutritional risks}

Maternal pre-pregnancy weight

In order to define the categories of weight that are not normal, the World Health Organization and the National Institutes of Health grouped weight into four categories according to individuals' body mass index: underweight $\left(<18.5 \mathrm{~kg} / \mathrm{m}^{2}\right)$, normal $\left(18.5-24.9 \mathrm{~kg} / \mathrm{m}^{2}\right)$, overweight $\left(25.0-29.9 \mathrm{~kg} / \mathrm{m}^{2}\right)$, and obese $\left(30.0 \mathrm{~kg} / \mathrm{m}^{2}\right)$ [49]. The literature shows a BMI-dependent relationship between pre-pregnancy obesity and adverse pregnancy outcomes $[50,51]$. Further, excessive postpartum weight retention is a risk not only for subsequent pregnancies $[52,53]$, but also for the development of maternal chronic diseases. Although guidelines exist for gestational weight gain according to maternal pre-pregnancy BMI, however gestational weight gain is not discussed further as it falls outside the scope of preconception care. Previous reviews have assessed maternal overweight and obesity using various cutoff points to define obesity, and have linked them to only one outcome of interest. This review extensively examines any $\mathrm{MNCH}$ outcomes that have been reported with all weight categories, grouping the data from individual studies into underweight or overweight and comparing these to women with normal BMI as defined above (please see table for data included here).

The review identified 34 studies that discussed maternal underweight $[11,13,15,30,31,54-81]$. This review found that pre-pregnancy underweight significantly increases the risk of preterm birth by $32 \%$ (RR 1.32, 95\% CI 1.22-1.43) (Figure 2). Pre-pregnancy underweight was also found to significantly increase the risk of small-for-gestational age babies (RR 1.64, 95\% CI 1.22-2.21)., Although previous work has found a significant effect of pre-pregnancy underweight on the risk of having low birth weight babies (RR 1.64 [82] and OR 1.82 [83], this review found a nonsignificant risk (RR $1.37,95 \%$ CI $0.46-4.13$ ) perhaps because of the low number of studies included since these were the only ones to assess maternal weight status before pregnancy. No effect was found for pre-pregnancy underweight on hypertensive disorders of pregnancy, GDM, large-for-gestational age or macrosomia, or any congenital birth defects.

The review identified 41 studies that reported outcomes for overweight women $[1,7,11,13,15,29,54-60$, 63-67,71-81,84-89]. The results presented in this review for the increased risk of hypertensive disorders of pregnancy with maternal overweight are not truly representative of the association since various studies categorized this outcome differently. The risk of preeclampsia (OR 2.28; 95\% CI: 2.04-2.55) (Figure 3) and GDM (OR 1.91; 95\% CI: 1.58-2.32), however, approximately doubles with 


\begin{tabular}{|c|c|c|c|c|c|c|}
\hline Study or Subgroup & log[Odds Ratio] & SE & Weight & $\begin{array}{c}\text { Odds Ratio } \\
\text { IV, Random, } 95 \% \mathrm{Cl}\end{array}$ & \multicolumn{2}{|c|}{$\begin{array}{c}\text { Odds Ratio } \\
\text { IV, Random, } 95 \% \mathrm{Cl}\end{array}$} \\
\hline Abenhaim 2007 & 0.131 & 0.0669 & $17.7 \%$ & $1.14[1.00,1.30]$ & & $=$ \\
\hline Chen 2009 & 0.0296 & 0.1827 & $4.2 \%$ & $1.03[0.72,1.47]$ & & $t$ \\
\hline Chen 2010 & -0.1625 & 0.2606 & $2.2 \%$ & $0.85[0.51,1.42]$ & & - \\
\hline Driul 2008 & 0.388 & 0.254 & $2.3 \%$ & $1.47[0.90,2.42]$ & & - \\
\hline Gilboa 2008 & 0.3646 & 0.2286 & $2.8 \%$ & $1.44[0.92,2.25]$ & & - \\
\hline Han 2010 & -0.0619 & 0.2552 & $2.3 \%$ & $0.94[0.57,1.55]$ & & - \\
\hline Johnson 2009 & 0.3365 & 0.03 & $29.2 \%$ & $1.40[1.32,1.48]$ & & a \\
\hline Kosa 2010 & 0.7467 & 0.3659 & $1.2 \%$ & $2.11[1.03,4.32]$ & & \\
\hline Murakami 2005 & 0.4383 & 0.5015 & $0.6 \%$ & $1.55[0.58,4.14]$ & & \\
\hline Ronnenberg 2003 & -0.1054 & 0.4137 & $0.9 \%$ & $0.90[0.40,2.02]$ & & \\
\hline Salihu 2009 & 0.3436 & 0.0147 & $33.4 \%$ & $1.41[1.37,1.45]$ & & a \\
\hline Wise 2010 & 0.5596 & 0.2232 & $3.0 \%$ & $1.75[1.13,2.71]$ & & 1 \\
\hline \multicolumn{2}{|l|}{ Total $(95 \% \mathrm{Cl})$} & & $100.0 \%$ & $1.32[1.22,1.43]$ & & 1 \\
\hline \multicolumn{5}{|c|}{$\begin{array}{l}\text { Heterogeneity: } \operatorname{Tau}^{2}=0.00 ; \mathrm{Chi}^{2}=21.95, \mathrm{df}=11(P=0.02) ;\left.\right|^{2}=50 \% \\
\text { Test for overall effect: } Z=6.94(P<0.00001)\end{array}$} & $\begin{array}{lcl}0.01 & 0.1 & 1 \\
\text { Favors normal weight }\end{array}$ & $\begin{array}{|cc|}10 & 100 \\
\text { Favors underweight }\end{array}$ \\
\hline \multicolumn{7}{|c|}{$\begin{array}{l}\text { Figure } 2 \text { Pre pregnancy underweight and risk for preterm birth: evidence from observational studies Citations to the included studies } \\
\text { Abenhaim } 2007 \text { [55], Chen } 2009 \text { [56], Driul } 2008 \text { [57], Johnson } 2009 \text { [58], Kosa } 2010 \text { [59], Murakami } 2005 \text { [60], Ronnenberg } 2003 \text { [61], Salihu } 2009 \\
\text { [62], Wise 2010[63], Chen } 2010 \text { [64], Gilboa } 2008 \text { [65], Han } 2010 \text { [66]. }\end{array}$} \\
\hline
\end{tabular}

pre-pregnancy overweight, and the effect was even greater for pre-pregnancy obesity. The data for impact of pre-pregnancy obesity is not presented since it is similar to the results for maternal overweight. The Pooled analysis of seven observational studies showed a clear increase of $42 \%$ in caesarean delivery among overweight women (OR 1.42, 95\% CI 1.21-1.66). This review found inconclusive evidence for the effect of pre-pregnancy overweight on preterm births, instrumental delivery, or fetal distress. Perinatal outcomes that were significantly associated with maternal overweight before conception include macrosomia, large-for-gestational age babies (OR 1.63, 95\% CI 1.51-1.76), and birth defects-notably neural tube defects and congenital heart defects (OR 1.15, 95\% CI 1.07-1.24).

\section{Nutritional interventions}

\section{Diet, exercise and weight loss}

Consumption of calorie-dense but nutritiously poor foods and physical inactivity are concerning for the health of all

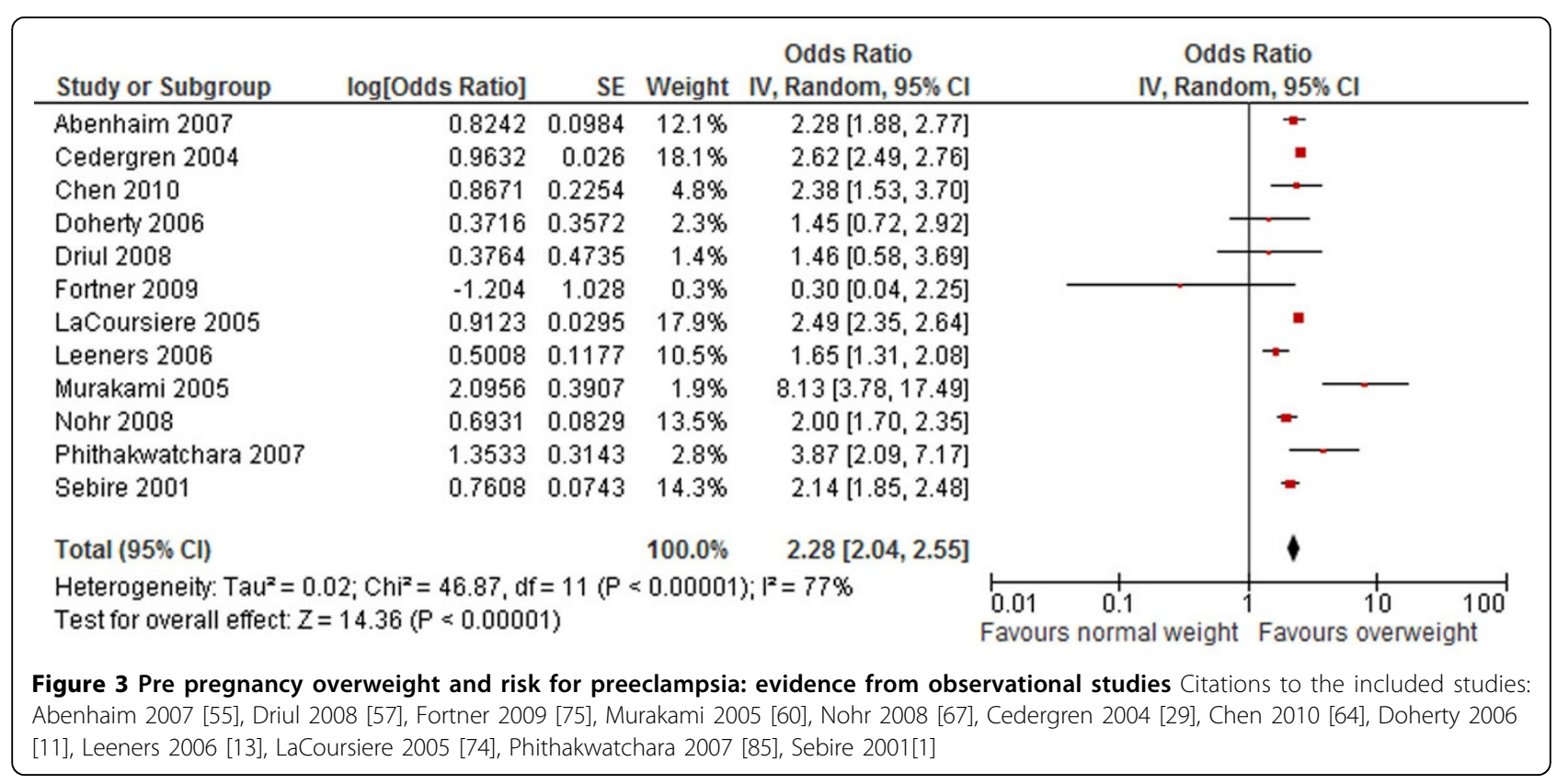


people, but disproportionately affect mothers and their young children. Fortunately, weight is a modifiable risk factor and evidence supports weight change as an intervention to improve $\mathrm{MNCH}$ outcomes $[50,51,56,73,90]$. Although this review demonstrated that maternal underweight increases the chances of preterm birth (25\%), and small-for-gestational age babies (64\%), the review found a scarcity of evidence for interventions to improve the macro-nutritional status of women before pregnancy.

As shown in the previous section, maternal overweight and obesity is a major risk factor for poor maternal and child outcomes. There is some evidence to support exercise as an intervention to decrease the risk of GDM, preeclampsia, and maternal weight gain, improve birth weight, and increase the chance of a normal delivery [91]. This review expands upon previous work [92,93] and examines whether diet and/or exercise are effective in reducing weight in women, and if this impacts $\mathrm{MNCH}$ outcomes.

The review 23 identified studies [94-116]. The trials found all used a control group; however they were carried out in women of different ages, and included different interventions. Women in the intervention group lost an average of up to $3.5 \mathrm{~kg}$. Interventions that combined calorie restriction and physical activity, involved a support system and monitoring, and were sustained over longer periods effected more weight change. A case control study [96] showed that women with perceived strenuous physical activity before pregnancy had a $78 \%$ reduced risk of preeclampsia.

\section{Folic acid supplementation}

Folic acid is a B-vitamin whose bioavailability from dietary sources lags behind that achieved through supplementation, and whose deficiency is associated with congenital abnormalities, especially neural tube defects [117]. Multiple case-control, cohort and quasi-randomised controlled trials have been carried out that provide a strong evidence base to support the effectiveness of folic acid supplementation in preventing birth defects and their consequent morbidity and mortality. Folic acid supplementation has thus become a primary periconceptional intervention.

The analyses showed that folic acid has a strong protective effect on preventing recurrent NTDs (RR 0.31, 95\% CI 0.14-0.66) when it was restricted to randomized doubleblind placebo-controlled studies, however this effect was no longer significant when two observational studies were included- (RR 0.43, 95\% CI 0.13-1.40) (Figure 4). The review also found a significant effect of multivitamin supplementation in preventing NTDs, both occurrent and recurrent, although the only included study that did not show a beneficial effect actually separated folic acid from multivitamins, while the rest included folic-acid containing supplements. Hence, it is doubtful that multivitamins without folic acid have a protective effect against NTDs, which is confirmed by the MRC study (RR for multivitamins versus placebo $0.61,95 \%$ CI $0.26-1.45$ ) [118].

Previous reviews have not shown a benefit of folic acid/ multivitamin supplementation on orofacial clefts, and although this review added three case-control studies and two prospective cohorts, the effect sizes adhered to unity. However, reviews that include all studies on folic acid/ multivitamin supplementation simultaneously do show a modest protective effect [123-126], especially for cleft lip.

This review identified [118-120,122,127-198] 73 studies on the effect of folic acid supplementation and congenital heart defects. The result is mixed at best- pooling of two randomized trials, one cohort and one case-control trial showed a risk reduction of $42 \%$ in this analysis (Figure 5).

No review has shown a consistent effect of folic acid/ multivitamin supplementation on maternal and pregnancy outcomes- including ectopic pregnancy, miscarriage, stillbirths, preterm births, low birth weight, and other birth defects. Further, the apprehension that widespread folic acid supplementation or fortification would lead to increased rates of multiple gestation was not shown to be significant in this review (RR 0.99, 95\% CI

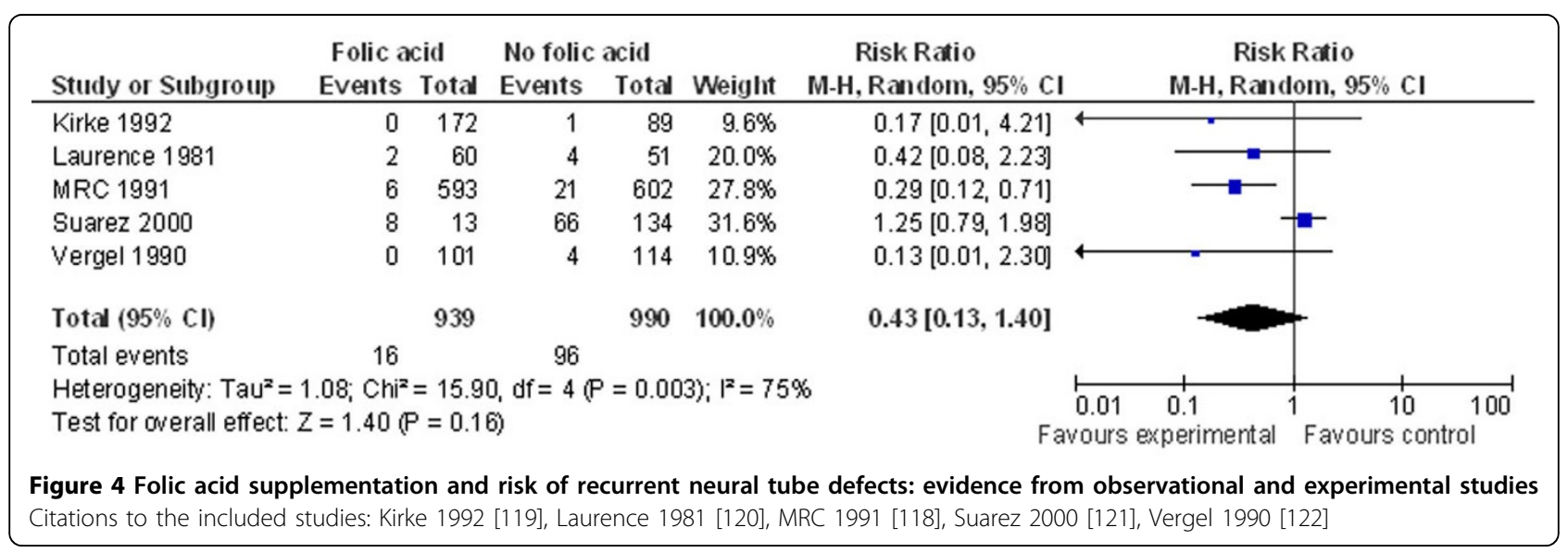




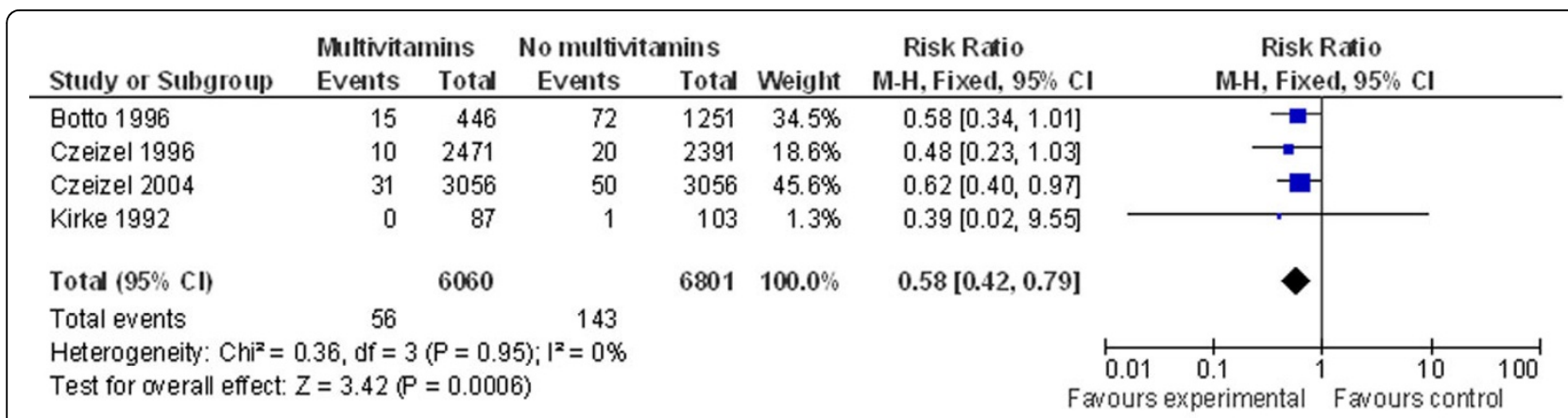

Figure 5 Folic acid supplementation and risk of congenital heart defects: evidence from observational and experimental studies Citations to the included studies: Botto 1996 [146], Czeizel 1996 [134], Czeizel 2004 [135], Kirke 1992 [119]

0.94-1.05) or previous work (OR 1.02 with supplementation and maximum annual increase in twinning rates of $4.6 \%$ with fortification) [199].

The results from three randomized double-blind placebocontrolled studies yield a $69 \%$ reduced risk (RR of $0.31,95 \%$ CI 0.14-0.66) for recurrent NTDs with periconceptional folic acid supplementation. The MRC study probably provides the most accurate estimate for this intervention since it was a multicenter prospective randomized trial [118]. The remaining studies all suffer from low response rates, however, only Suarez et al. 2000 [121] has results inconsistent with the pooled analysis. This could be attributed to recall and selection bias in the study or to primary intake in this population being from dietary sources with lower bioavailability.

\section{Multivitamins supplementation}

There is incontrovertible data to support the routine use of multivitamins by women of reproductive age, to improve their own health as well as their potential mother and child outcomes. Although previous systematic reviews and meta-analyses have analysed the unique role of periconceptional folic acid (versus multivitamins) on $\mathrm{MNCH}$ outcomes, they have included only randomised and quasirandomised trials. In addition, while periconceptional supplementation is in itself an intervention, it would have a greater impact if it were implemented for all women with the potential to become mothers. For limb reduction defects (RR ranges from 0.43-0.59 for all analyses) and congenital urinary tract anomalies (RR ranges from 0.17 0.68 for all analyses), the evidence shows a modest but persistent risk reduction with the use of multivitamins, rather than folic acid.

Pooling two cohort studies, the review also found a significant $27 \%$ reduction in the risk of preeclampsia (Figure 6) by maternal periconceptional multivitamin supplementation. This review also found a $43 \%$ risk reduction of multivitamins for multiple congenital abnormalities (Figure 7).

Pooling data from 5 case-control and 2 cohort-controlled trials conducted in relatively high-income countries (HICs), resulted in a significant $49 \%$ decrease in risk (RR 0.51, 95\% CI 0.31-0.82) (Figure 8) of occurrent neural tube defects due to periconceptional multivitamin supplementation. The case-control study by Bower \& Stanley 1992 was inconsistent with the other study results, possibly owing to the small total number of women using periconceptional multivitamins, or to recall bias among case mothers [129]. There was substantial heterogeneity between studies, however repeat analysis using random effects did not change the results.

A recent community intervention in China [201] provided multivitamins to the intervention group from 3 months pre-pregnancy until the end of the first trimester.

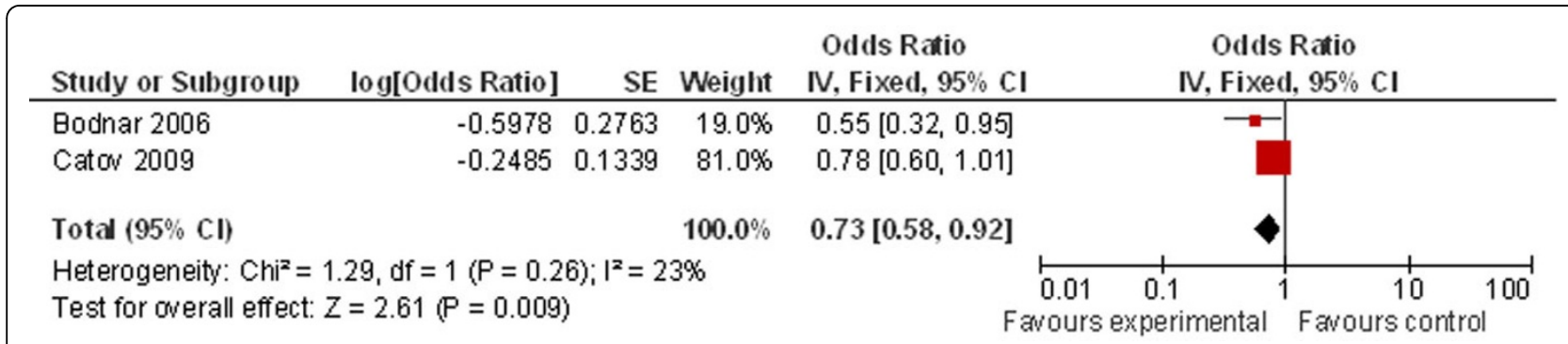

Figure 6 Multivitamin supplementation and risk of preeclampsia: evidence from observational studies Citations to the included studies: Bodnar 2006 [155], Catov 2009 [156] 


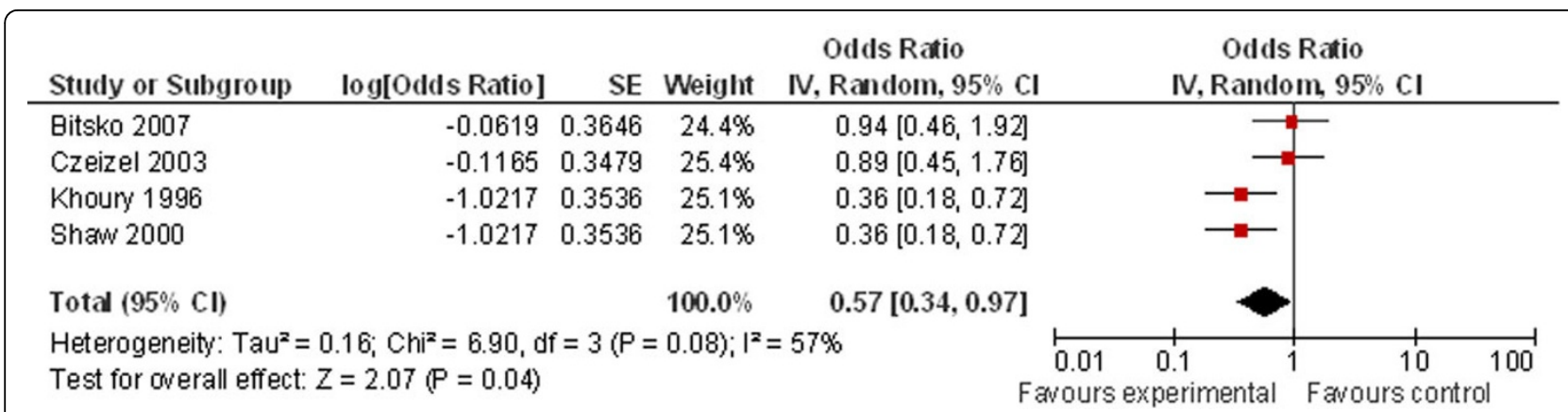

Figure 7 multivitamin supplementation and risk of multiple congenital anomalies: evidence from observational studies Citations to the included studies: Bitsko 2007 [149], Czeizel 2003 [150], Khoury 1996 [151], Shaw 2000 [152]

The intervention resulted in lower incidence of stillbirth $(0.70 \%$ in intervention group vs. $1.55 \%$ in control group; $\mathrm{p}<0.001)$, malformation $(0.23 \%$ in intervention group vs. $0.70 \%$ in control group; $\mathrm{p}<0.001)$ and low birth weight $(0.39 \%$ in intervention group vs. $0.84 \%$ in control group; $\mathrm{p}<0.001)$ compared to the control group, and better growth indicators at birth.

\section{Iron supplementation}

Anemia is a common problem among women of reproductive age, especially in low and middle income countries (LMICs) where low dietary intake of bioavailable iron combined with endemic infectious diseases such as helminthiasis puts women at increased risk in the preconception period. Low preconception hemoglobin and ferritin levels increase the risk of poor fetal growth and low birth weight [202]. The literature shows that iron supplementation during pregnancy can be a protective factor against low birth weight [203], and given alone or with folic acid it is effective in increasing iron stores and preventing anemia during later gestation [204].
The review identified 6 studies [205-210]. Berger et al. [205] tested a weekly combined iron-folic acid intervention in the preconception period among Vietnamese women and similarly found the supplementation significantly improved iron status and reduced anemia when compared to baseline. In the Philippines ferritin levels improved, however hemoglobin lagged behind, possibly due to women being deficient in other micronutrients related to heme formation which were not supplemented during the study [206]. The results of these interventions on a national level were similar to a previous randomized-controlled trial in Bangladesh [207] where iron-folic acid given as a powdered supplement added to food decreased anemia among non-pregnant women; however this benefit did not extend to those women who became pregnant. Recent trials in Vietnam [208,209] combined iron-folic acid supplementation with intermittent deworming and demonstrated significant reduction in anemia, lower rates of helminthic infection, high compliance, and increase in birth weight in intervention districts versus control. In India, the country with the world's highest proportion of maternal anemia, the same intervention was carried out in

\begin{tabular}{|c|c|c|c|c|c|c|c|c|}
\hline \multirow[b]{2}{*}{ Study or Subgroup } & \multicolumn{2}{|c|}{ Multivitamins } & \multicolumn{2}{|c|}{ No multivitamins } & \multirow[b]{2}{*}{ Weight } & \multirow{2}{*}{$\begin{array}{c}\text { Risk Ratio } \\
\text { M-H, Random, } 95 \% \mathrm{Cl}\end{array}$} & \multirow{2}{*}{\multicolumn{2}{|c|}{$\begin{array}{c}\text { Risk Ratio } \\
\text { M-H, Random, } 95 \% \mathrm{Cl} \\
\end{array}$}} \\
\hline & Events & Total & Events & Total & & & & \\
\hline Bower 1992 & 9 & 21 & 66 & 204 & $17.5 \%$ & $1.32[0.78,2.26]$ & & -- \\
\hline Chen 2008 & 9 & 25444 & 48 & 26599 & $15.0 \%$ & $0.20[0.10,0.40]$ & $\longrightarrow$ & \\
\hline Czeizel 1996 & 0 & 2471 & 6 & 2391 & $2.5 \%$ & $0.07[0.00,1.32]$ & $\longleftarrow$ & \\
\hline Czeizel 2004 & 1 & 3056 & 9 & 3056 & $4.4 \%$ & $0.11[0.01,0.88]$ & & \\
\hline Mulinare 1988 & 24 & 435 & 159 & 1251 & $19.1 \%$ & $0.43[0.29,0.66]$ & - & \\
\hline Shaw 1995 & 88 & 186 & 207 & 356 & $21.5 \%$ & $0.81[0.68,0.97]$ & - & \\
\hline Werler 1993 & 34 & 373 & 250 & 1503 & $20.0 \%$ & $0.55[0.39,0.77]$ & - & \\
\hline Total $(95 \% \mathrm{Cl})$ & & 31986 & & 35360 & $100.0 \%$ & $0.51[0.31,0.82]$ & & \\
\hline Total events & 165 & & 745 & & & & & \\
\hline $\begin{array}{l}\text { Heterogeneity: } \operatorname{Tau}^{2}= \\
\text { Test for overall effect }\end{array}$ & $\begin{array}{l}0.28 ; \mathrm{Chi}^{2} \\
\mathrm{Z}=2.75(\mathrm{~F}\end{array}$ & $\begin{array}{l}=38.40 \\
=0.006\end{array}$ & $d f=6(P<$ & 00001); I & $I^{2}=84 \%$ & Favo & 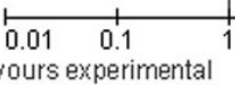 & $\begin{array}{l}10 \\
10 \\
\text { Favours control }\end{array}$ \\
\hline
\end{tabular}


adolescent girls, resulting in a substantial drop in anemia prevalence [210].

\section{Discussion}

Maternal overweight and obesity is a growing problem across the world, but women in LMICs and lower socioeconomic strata continue to be at risk of undernourishment [211]. Both pre-pregnancy overweight and underweight are risk factors for poor maternal and child health outcomes, however overweight and obesity results in significantly greater health risks and associated costs. This review identified the association of maternal underweight with preterm birth and small for gestational age babies and the findings are comparable to previous meta-analysis which showed an increased risk of 29\% [212] and another study which showed an increased risk of 37\% [62]. Similarly the results on association of pre-pregnancy overweight on pre-eclampsia and GDM is consistent with previous reviews that show the risk of preeclampsia typically doubles for each 5 to $7 \mathrm{~kg} / \mathrm{m}^{2}$ increase in BMI [213]; and the OR of developing GDM is 1.97-2.14 for overweight women, and 3.01-3.56 for obese women [16,214]. The pooled analysis on risk of caseation section and other outcomes are also consistent with previous reviews $[2,6,16,215,216]$. Given that weight is a modifiable risk factor, research must now focus on how healthcare interventions and public health campaigns can reduce these risks.

There is a strong need for evidence to demonstrate the effectiveness of interventions to achieve optimal prepregnancy weight, especially for those women who are underweight. This review confirms earlier evidence [217] that promoting improvement in diet and exercise through sustained, daily changes, with the help of a support system results in weight loss and higher levels of physical activity. Although preceding work illustrates examples of population-scale interventions, more research is needed to support how small-scale initiatives targeted at women with childbearing potential can be implemented on a wider scale. In HICs countries, obese women are increasingly opting to undergo weight loss surgeries, and a review of laparoscopic adjustable gastric banding (LAGB) shows lower gestational weight gain and better maternal and neonatal outcomes for these women compared to obese women not undergoing LAGB prior to pregnancy; however the outcomes were not improved compared to women of normal weight [218].

The role of nutrition in promoting health is well defined. What women eat determines more than just their own health, it is also vital to healthy pregnancies and newborns, and in fact research now shows that nutritional status in early childhood affects health throughout life. Pregnancy, or planning for pregnancy, provides an impetus for women to change non-healthful behaviors. Many women are still unaware of how much their nutritional status impacts their pregnancy outcomes, and improving women's nutrition and weight-related behaviors should therefore begin during their earlier reproductive years.

Folic acid supplementation has been proven to reduce the risk of NTDs, both recurrent and occurrent and the results are confirmed by the meta-analyses undertaken by De-Regil et al. [37] However, further research is needed to show whether this benefit extends to prevention of orofacial clefts and congenital cardiovascular abnormalities. Although major health organizations promote the use of folic acid by women of reproductive age through clinical guidelines and recommendations [219], and the prevalence of folic acid use is reportedly high in the prenatal period, most women do not use folic acid in the periconceptional period, even if they are aware of its benefits. A recent systematic review [41] demonstrated that even in high income countries, only half of all women use folic acid before conception, therefore protective levels cannot be achieved before the critical period of neural tube closure. Reasons for low prevalence of use are confirmed by other studies [220-228] and include low maternal education and socioeconomic status; young maternal age; lack of a partner; and unplanned pregnancy. It is necessary therefore to improve awareness and use of folic acid supplements among all women of reproductive age so that even women with unplanned pregnancies are protected.

Multicomponent interventions increase use transiently and do not achieve universal coverage, although those with personal counseling in addition to mass campaigns have been shown to be more effective [229]. Fortification has thus been proposed as a means to prevent approximately half of all NTDs occurring annually and $13 \%$ of neonatal mortality attributed to NTDs [40], especially in areas with high prevalence of NTDs [230-232]. However, ongoing efforts must be made to supplement women at risk of a recurrent NTDs and women who are more folate-depleted [233,234]. A novel idea has been to incorporate folate into contraceptive pills, which also helps to bridge the gap between when a woman discovers she is pregnant and neural tube closure, even without periconceptional folate use [235]. In order to provide all women (including those at risk of recurrence) with an adequate dose of folic acid, public health policy in some countries now mandates that staple foods, such as flour, be fortified with folic acid.

The studies on iron demonstrate that large-scale nutritional intervention is feasible in LMICs contexts, and results in better biochemical indices. Given the global magnitude of maternal anemia, however, it is surprising that only one trial further assessed birth weight as a measure of improved maternal and newborn health. Iron fortification of foods such as flour, rice, sugar, juice, and fish or soy sauce in various countries has also been shown to improve iron status among women of 
reproductive age [236-240], but again the analyses of the fortification trials do not assess pregnancy outcomes in the long-term. As with folic acid, preventive iron supplementation may require greater community mobilization and social marketing for increased effectiveness [205] and to contribute to improved women's and maternal health in developing regions.

\section{Conclusion}

Maternal malnutrition remains a serious global health issue, particularly in LMICs. The median prevalence of low body mass index among women in the preconception period is $10.9 \%$ among 24 countries with a recent Demographic and Health Survey, while $42 \%$ of women are anemic when they become pregnant [241]. Underweight and deficiencies of essential nutrients coupled with the increasing burden of obesity have consequences during pregnancy and for newborns. These negative effects are amplified in adolescents or women with closely-spaced pregnancies since they have depleted nutritional reserves, which results in stillbirths, neonatal deaths, low birth weight and preterm births [242]. Overweight and obesity further predispose to maternal hypertensive disorders and gestational diabetes.

Among nutrition-specific interventions periconceptional folic acid supplementation significantly reduces the risk of recurrent NTDs. There is growing interest in multiple micronutrient supplementation in at-risk populations in whom multiple deficiencies often coexist. Data for multiple micronutrient supplementation from a small number of controlled trials shows a persistent lowering of rates of congenital anomalies and preeclampsia. Other nutritionspecific interventions (iron, calcium, balanced protein energy supplementation) have only been studied in pregnant women, or if they have been studied during the preconception period the outcomes are limited to changes in biochemical markers while pregnancy and birth outcomes were not assessed.

Strategies for implementation of nutrition-specific interventions in the preconception period are needed especially to reach women in low- and middle-income countries. At present, food fortification with micronutrients is noted to be the most cost-effective large scale method. However, different approaches are needed to specifically increase uptake among women of reproductive age, noting the critical links between poor maternal nutritional status and its wide-ranging determinants and consequences. Nutritionalsensitive interventions improve population health, education and development and countries investing in such strategies have had greater gains in both nutrition and health outcomes. Integrating nutrition with maternal and child health initiatives and developing community-based platforms that are able to reach populations are especially promising.

\section{Peer review}

Peer review reports are included in additional file 1.

\section{Additional material}

Additional file 1: Peer review reports.

\section{Competing interests}

We do not have any financial or non-financial competing interests for this review.

\section{Acknowledgment}

The publication of these papers and supplement was supported by an unrestricted grant from The Partnership for Maternal, Newborn and Child Health.

\section{Declarations}

This article has been published as part of Reproductive Health Volume 11 Supplement 2, 2014: Preconception interventions. The full contents of the supplement are available online at http://www.reproductive-health-journal. com/supplements/11/S3. Publication charges for this collection were funded by the Partnership for Maternal, Newborn \& Child Health (PMNCH).

Published: 26 September 2014

\section{References}

1. Sebire NJ, Jolly M, Harris JP, Wadsworth J, Joffe M, Beard RW, Regan L, Robinson S: Maternal obesity and pregnancy outcome: a study of 287213 pregnancies in London. International journal of obesity 2001, 25(8):1175-1182

2. Arendas K, Qiu Q, Gruslin A: Obesity in pregnancy: pre-conceptional to postpartum consequences. J Obstet Gynaecol Can 2008, 30(6):477-488.

3. Hall LF, Neubert AG: Obesity and pregnancy. Obstetrical \& gynecological survey 2005, 60(4):253.

4. Rode L, Nilas L, Wøjdemann K, Tabor A: Obesity-related complications in Danish single cephalic term pregnancies. Obstetrics \& Gynecology 2005, 105(3):537.

5. Rosenberg TJ, Garbers S, Chavkin W, Chiasson MA: Prepregnancy weight and adverse perinatal outcomes in an ethnically diverse population. Obstetrics \& Gynecology 2003, 102(5 Part 1):1022.

6. $\mathrm{Yu} \mathrm{CKH}$, Teoh TG, Robinson S: Obesity in pregnancy. BJOG: An International Journal of Obstetrics \& Gynaecology 2006, 113(10):1117-1125.

7. Callaway LK, Prins JB, Chang AM, Mclntyre HD: The prevalence and impact of overweight and obesity in an Australian obstetric population. Medical Journal of Australia 2006, 184(2):56.

8. Black RE, Allen LH, Bhutta ZA, Caulfield LE, de Onis M, Ezzati M, Mathers C, Rivera J: Maternal and child undernutrition: global and regional exposures and health consequences. Lancet 2008, 371(9608):243-260.

9. Bhutta ZA, Chopra M, Axelson H, Berman P, Boerma T, Bryce J, Bustreo F, Cavagnero E, Cometto G, Daelmans B: Countdown to 2015 decade report (2000-10): taking stock of maternal, newborn, and child survival. Lancet 2012, 375(9730):2032-2044.

10. Baeten JM, Bukusi EA, Lambe M: Pregnancy complications and outcomes among overweight and obese nulliparous women. American Journal of Public Health 2001, 91(3):436.

11. Doherty DA, Magann EF, Francis J, Morrison JC, Newnham JP: Prepregnancy body mass index and pregnancy outcomes. International Journal of Gynecology \& Obstetrics 2006, 95(3):242-247.

12. Bodnar LM, Wisner KL, Moses-Kolko E, Sit DKY, Hanusa BH: Prepregnancy body mass index, gestational weight gain and the likelihood of major depression during pregnancy. The Journal of clinical psychiatry 2009, 70(9):1290.

13. Leeners B, Rath W, Kuse S, Irawan C, Imthurn B, Neumaier-Wagner P: BMI: new aspects of a classical risk factor for hypertensive disorders in pregnancy. Clinical Science 2006, 111:81-86.

14. Robinson HE, O'Connell CM, Joseph KS, McLeod NL: Maternal outcomes in pregnancies complicated by obesity. Obstetrics \& Gynecology 2005 106(6):1357 
15. Samuels-Kalow ME, Funai EF, Buhimschi C, Norwitz E, Perrin M, CalderonMargalit R, Deutsch L, Paltiel O, Friedlander Y, Manor O: Prepregnancy body mass index, hypertensive disorders of pregnancy, and long-term maternal mortality. American journal of obstetrics and gynecology 2007, 197(5):490.

16. Chu SY, Kim SY, Schmid CH, Dietz PM, Callaghan WM, Lau J, Curtis KM: Maternal obesity and risk of cesarean delivery: a meta analysis. Obesity Reviews 2007, 8(5):385-394.

17. Lu GC, Rouse DJ, DuBard M, Cliver S, Kimberlin D, Hauth JC: The effect of the increasing prevalence of maternal obesity on perinatal morbidity* 1 . American journal of obstetrics and gynecology 2001, 185(4):845-849.

18. Li R, Jewell S, Grummer-Strawn L: Maternal obesity and breast-feeding practices. American Journal of Clinical Nutrition 2003, 77(4):931.

19. Hilson JA, Rasmussen KM, Kjolhede CL: High prepregnant body mass index is associated with poor lactation outcomes among white, rural women independent of psychosocial and demographic correlates. Journal of Human Lactation 2004, 20(1):18.

20. Saravanakumar K, Rao SG, Cooper GM: Obesity and obstetric anaesthesia. Anaesthesia 2006, 61(1):36-48

21. Stotland $N E$, Washington $A E$, Caughey $A B$ : Prepregnancy body mass index and the length of gestation at term. American journal of obstetrics and gynecology 2007, 197(4):378.

22. Rayco-Solon P, Fulford AJ, Prentice AM: Maternal preconceptional weight and gestational length. American journal of obstetrics and gynecology 2005, 192(4):1133-1136.

23. Myles TD, Gooch J, Santolaya J: Obesity as an independent risk factor for infectious morbidity in patients who undergo cesarean delivery. Obstetrics \& Gynecology 2002, 100(5 Part 1):959.

24. Bujold E, Hammoud A, Schild C, Krapp M, Baumann P: The role of maternal body mass index in outcomes of vaginal births after cesarean. American journal of obstetrics and gynecology 2005, 193(4):1517-1521.

25. Carroll CS: Vaginal birth after cesarean section versus elective repeat cesarean delivery: Weight-based outcomes* 1 . American journal of obstetrics and gynecology 2003, 188(6):1516-1522

26. Durnwald CP, Ehrenberg HM, Merce BM: The impact of maternal obesity and weight gain on vaginal birth after cesarean section success. American journal of obstetrics and gynecology 2004, 191(3):954-957.

27. Goodall PT, Ahn JT, Chapa JB, Hibbard JU: Obesity as a risk factor for failed trial of labor in patients with previous cesarean delivery. American journal of obstetrics and gynecology 2005, 192(5):1423-1426.

28. Stephansson O, Dickman PW, Johansson A, Cnattingius S: Maternal weight, pregnancy weight gain, and the risk of antepartum stillbirth* 1 . American journal of obstetrics and gynecology 2001, 184(3):463-469.

29. Cedergren MI: Maternal morbid obesity and the risk of adverse pregnancy outcome. Obstetrics \& Gynecology 2004, 103(2):219.

30. Kristensen J, Vestergaard M, Wisborg K, Kesmodel U, Secher NJ: Pre pregnancy weight and the risk of stillbirth and neonatal death. BJOG: An International Journal of Obstetrics \& Gynaecology 2005, 112(4):403-408.

31. Nohr EA, Bech BH, Davies MJ, Frydenberg M, Henriksen TB, Olsen J: Prepregnancy obesity and fetal death: a study within the Danish National Birth Cohort. Obstetrical \& gynecological survey 2005, 61(1):7.

32. Kitsantas P, P L: Maternal obesity, health status during pregnancy, and breastfeeding initiation and duration. 2010.

33. Mesman I, R T, Bonsel GJ, Gemke RJ, van der Wal MF, Vrijkotte TG: Maternal pre-pregnancy body mass index explains infant's weight and BMI at 14 months: results from a multi-ethnic birth cohort study. 2009.

34. Olson CM, S M, Dennison BA: Maternal weight gain during pregnancy and child weight at age 3 years. 2009.

35. Ellen A Nohr1, M V, Jennifer L Baker1, Thorkild IA Sørensen1, Jorn Olsen1, Kathleen M Rasmussen1: Combined associations of prepregnancy body mass index and gestational weight gain with the outcome of pregnancy1,2,. 2008.

36. Lu GC, Rouse DJ, DuBard M, Cliver S, Kimberlin D, Hauth JC: The effect of the increasing prevalence of maternal obesity on perinatal morbidity. American Journal of Obstetrics and Gynecology 2001, 185(4):845-849.

37. De-Regil LM, Fernández-Gaxiola AC, Dowswell T, Peña-Rosas JP: Effects and safety of periconceptional folate supplementation for preventing birth defects. Cochrane Database of Systematic Reviews 2010, 10:CD00795.

38. Grosse SD, Collins JS: Folic acid supplementation and neural tube defect recurrence prevention. Birth Defects Research Part A: Clinical and Molecular Teratology 2007, 79(11):737-742.
39. Blom HJ: Folic acid, methylation and neural tube closure in humans. Birth Defects Research Part A: Clinical and Molecular Teratology 2009, 85(4):295-302.

40. Blencowe H, Cousens S, Modell B, Lawn J: Folic acid to reduce neonatal mortality from neural tube disorders. International Journal of Epidemiology 2010, 39(Supplement 1):i110.

41. Ray JG, Vermeulen MJ, Meier C, Wyatt PR: Risk of congenital anomalies detected during antenatal serum screening in women with pregestational diabetes. Qjm 2004, 97(10):651.

42. Ramakrishnan U, Lowe A, Vir S, Kumar S, Mohanraj R, Chaturvedi A, Noznesky EA, Martorell R, Mason JB: Public health interventions, barriers, and opportunities for improving maternal nutrition in India. Food Nutr Bull 2012, 33(2 Suppl):S71-92.

43. Dean SV, Lassi ZS, Imam AM, Bhutta ZA: Preconception Care: closing the gap in the continuum of care to accelerate improvements in maternal, newborn and child health. Reproductive Health 2014.

44. Dean S, Rudan I, Althabe F, Girard AW, Howson C, Langer A, Lawn J, Reeve M-E, Teela KC, Toledano M: Setting research priorities for preconception care in low-and middle-income countries: aiming to reduce maternal and child mortality and morbidity. PLoS Med 2013, 10(9):e1001508.

45. WHO WHO: Meeting to develop a global consensus on preconception care to reduce maternal and childhood mortality and morbidity. Geneva: World Health Organization Headquarters; 8211

46. Cochrane Handbook for Systematic Reviews of Interventions. Version 5.0.0 [updated February 2008]. In The Cochrane Collaboration Higgins JPT, Green S 2008, Available from http://www.cochranehandbook.org.

47. Brand RA: Editorial: standards of reporting: the CONSORT, QUORAM, and STROBE guidelines. Clin Orthop Relat Res 2009.

48. Review Manager (RevMan). [computer program]. Version 5.0: Copenhagen: Nordic Cochrane Collaboration; 2008

49. World Health Organization: Obesity: Preventing and Managing the Global Epidemic. WHO Obesity Technical Report Series 894. Geneva, Switzerland: World Health Organization; 2000.

50. Raatikainen K, Heiskanen N, Heinonen S: Transition from Overweight to Obesity Worsens Pregnancy Outcome in a BMI-dependent Manner\&ast. Obesity 2006, 14(1):165-171.

51. Villamor $E$, Cnattingius $S$ : Interpregnancy weight change and risk of adverse pregnancy outcomes: a population-based study. The Lancet 2006, 368(9542):1164-1170.

52. Hoff GL, Cai J, Okah FA, Dew PC: Pre-Pregnancy Overweight Status between Successive Pregnancies and Pregnancy Outcomes. Journal of Women's Health 2009, 18(9):1413-1417.

53. Joseph NP, Hunkali KB, Wilson B, Morgan E, Cross M, Freund KM: Prepregnancy body mass index among pregnant adolescents: gestational weight gain and long-term post partum weight retention. Journal of Pediatric and Adolescent Gynecology 2008, 21(4):195-200.

54. Ota E, Haruna M, Suzuki M, Anh DD, Tho LH, Tam NTT, Thiem VD, Anh NTH, Isozaki M, Shibuya K: Maternal body mass index and gestational weight gain and their association with perinatal outcomes in Viet Nam. Bulletin of the World Health Organization 2011, 89(2):127-136.

55. Abenhaim HA, Kinch RA, Morin L, Benjamin A, Usher R: Effect of prepregnancy body mass index categories on obstetrical and neonatal outcomes. Archives of Gynecology and Obstetrics 2007, 275(1):39-43.

56. Chen A, Klebanoff MA, Basso O: Pre-pregnancy body mass index change between pregnancies and preterm birth in the following pregnancy. Paediatric and Perinatal Epidemiology 2009, 23(3):207-215.

57. Driul L, Cacciaguerra G, Citossi A, Martina MD, Peressini L, Marchesoni D: Prepregnancy body mass index and adverse pregnancy outcomes. Archives of Gynecology and Obstetrics 2008, 278(1):23-26.

58. Johnson TS, Rottier KJ, Luellwitz A, Kirby RS: Maternal prepregnancy body mass index and delivery of a preterm infant in Missouri 1998-2000. Public Health Nursing 2009, 26(1):3-13.

59. Kosa JL, Guendelman S, Pearl M, Graham S, Abrams B, Kharrazi M: The Association Between Pre-pregnancy BMI and Preterm Delivery in a Diverse Southern California Population of Working Women. Maternal and Child Health Journal 2010, 1-10.

60. Murakami M, Ohmichi M, Takahashi T, Shibata A, Fukao A, Morisaki N, Kurachi H: Prepregnancy body mass index as an important predictor of perinatal outcomes in Japanese. Archives of Gynecology and Obstetrics 2005, 271(4):311-315 
61. Ronnenberg AG, Wang X, Xing H, Chen C, Chen D, Guang W, Guang A, Wang $L$, Ryan $L, X u X$ : Low preconception body mass index is associated with birth outcome in a prospective cohort of Chinese women. Journal of Nutrition 2003, 133(11):3449.

62. Salihu HM, Mbah AK, Alio AP, Clayton HB, Lynch O: Low pre-pregnancy body mass index and risk of medically indicated versus spontaneous preterm singleton birth. European Journal of Obstetrics \& Gynecology and Reproductive Biology 2009, 144(2):119-123.

63. Wise LA, Palmer JR, Heffner LJ, Rosenberg L: Prepregnancy body size, gestational weight gain, and risk of preterm birth in African-American women. Epidemiology 2010, 21(2):243.

64. Chen CW, Tsai CY, Sung FC, Lee YY, Lu TH, Li CY, Ko MC: Adverse birth outcomes among pregnancies of teen mothers: age specific analysis of national data in Taiwan. Child: Care, Health and Development 2010, 36(2):232-240.

65. Gilboa SM, Correa A, Alverson CJ: Use of spline regression in an analysis of maternal prepregnancy body mass index and adverse birth outcomes: does it tell us more than we already know? Annals of epidemiology 2008, 18(3):196-205.

66. Han YS, Ha EH, Park HS, Kim YJ, Lee SS: Relationships between pregnancy outcomes, biochemical markers and pre-pregnancy body mass index. International Journal of Obesity 2010.

67. Nohr EA, Vaeth M, Baker JL, Sorensen TIA, Olsen J, Rasmussen KM Combined associations of prepregnancy body mass index and gestational weight gain with the outcome of pregnancy. American Journal of Clinical Nutrition 2008, 87(6):1750.

68. Watanabe $H$, Inoue $K$, Doi M, Matsumoto M, Ogasawara K, Fukuoka $H$, Nagai $Y$ : Risk factors for term small for gestational age infants in women with low prepregnancy body mass index. Journal of Obstetrics and Gynaecology Research 2010, 36(3):506-512.

69. Frederick IO, Williams MA, Sales AE, Martin DP, Killien M: Pre-pregnancy body mass index, gestational weight gain, and other maternal characteristics in relation to infant birth weight. Maternal and Child Health Journal 2008, 12(5):557-567.

70. Yekta Z, Ayatollahi H, Porali R, Farzin A: The effect of pre-pregnancy body mass index and gestational weight gain on pregnancy outcomes in urban care settings in Urmia-Iran. BMC Pregnancy and Childbirth 2006, 6(1):15.

71. Chu SY, Bachman DJ, Callaghan WM, Whitlock EP, Dietz PM, Berg CJ, O'Keeffe-Rosetti M, Bruce FC, Hornbrook MC: Association between obesity during pregnancy and increased use of health care. New England Journal of Medicine 2008, 358(14):1444.

72. Dietz PM, Callaghan WM, Morrow B, Cogswell ME: Population-based assessment of the risk of primary cesarean delivery due to excess prepregnancy weight among nulliparous women delivering term infants. Maternal and Child Health Journal 2005, 9(3):237-244.

73. Getahun D, Ananth CV, Peltier MR, Salihu HM, Scorza WE: Changes in prepregnancy body mass index between the first and second pregnancies and risk of large-for-gestational-age birth. American journal of obstetrics and gynecology 2007, 196(6):530.

74. LaCoursiere D, Bloebaum L, Duncan JD, Varner MW: Population-based trends and correlates of maternal overweight and obesity, Utah 19912001. American journal of obstetrics and gynecology 2005, 192(3):832-839.

75. Fortner RT, Pekow P, Solomon CG, Markenson G, Chasan-Taber L: Prepregnancy body mass index, gestational weight gain, and risk of hypertensive pregnancy among Latina women. American Journal of Obstetrics and Gynecology 2009, 200(2):167-167.

76. Saftlas AF, Wang W, Risch H, Woolson R, Hsu CD, Bracken MB: Prepregnancy body mass index and gestational weight gain as risk factors for preeclampsia and transient hypertension. Annals of epidemiology 2000, 10(7):475-475.

77. Gilboa SM, Correa A, Botto LD, Rasmussen SA, Waller DK, Hobbs CA Cleves MA, Riehle-Colarusso TJ: Association between prepregnancy body mass index and congenital heart defects. American Journal of Obstetrics and Gynecology 2010, 202(1):51.

78. Oddy WH, De Klerk NH, Miller M, Payne J, Bower C: Association of maternal pre pregnancy weight with birth defects: Evidence from a case-control study in Western Australia. Australian and New Zealand Journal of Obstetrics and Gynaecology 2009, 49(1):11-15.

79. Waller DK, Shaw GM, Rasmussen SA, Hobbs CA, Canfield MA, Siega-Riz AM, Gallaway MS, Correa A: Prepregnancy obesity as a risk factor for structural birth defects. Archives of Pediatrics and Adolescent Medicine 2007, 161(8):745.
80. Li Z, Liu J, Ye R, Zhang L, Pei L, Zheng X, Ren A: Maternal prepregnancy body mass index and risk of neural tube defects: A population-based case-control study in Shanxi province, China. Birth Defects Research Part A: Clinical and Molecular Teratology 2010.

81. Waller DK, Tita ATN, Werler MM, Mitchell AA: Association between prepregnancy maternal body mass index and the risk of having an infant with a congenital diaphragmatic hernia. Birth Defects Research Part A: Clinical and Molecular Teratology 2003, 67(1):73-76.

82. Han Z, Mulla S, Beyene J, Liao G, McDonald SD: Maternal underweight and the risk of preterm birth and low birth weight: a systematic review and meta-analyses. International Journal of Epidemiology 2011, 40(1):65.

83. Salihu HM, Lynch ON, Alio AP, Mbah AK, Kornosky JL, Marty PJ: Extreme maternal underweight and feto-infant morbidity outcomes: a populationbased study. Journal of Maternal-Fetal and Neonatal Medicine 2009, 22(5):428-434.

84. Jensen DM, Damm P, Sørensen B, Mølsted-Pedersen L, Westergaard JG, Ovesen $\mathrm{P}$, Beck-Nielsen $\mathrm{H}$ : Pregnancy outcome and prepregnancy body mass index in 2459 glucose-tolerant Danish women. American journal of obstetrics and gynecology 2003, 189(1):239-244

85. Phithakwatchara N, Titapant $\mathrm{V}$ : The effect of pre-pregnancy weight on delivery outcome and birth weight in potential diabetic patients with normal screening for gestational diabetes mellitus in Siriraj Hospital. JOURNAL-MEDICAL ASSOCIATION OF THAILAND 2007, 90(2):229.

86. Barau $G$, Robillard $P$ : Linear association between maternal pre pregnancy body mass index and risk of caesarean section in term deliveries. BJOG: An International Journal of Obstetrics \& Gynaecology 2006, 113(10):1173-1177.

87. Kaiser PS, Kirby RS: Obesity as a risk factor for cesarean in a low-risk population. Obstetrics \& Gynecology 2001, 97(1):39.

88. Vahratian A, Siega-Riz AM, Savitz DA, Zhang J: Maternal pre-pregnancy overweight and obesity and the risk of cesarean delivery in nulliparous women. Annals of epidemiology 2005, 15(7):467-474.

89. Frederick 1O, Rudra CB, Miller RS, Foster JC, Williams MA: Adult weight change, weight cycling, and prepregnancy obesity in relation to risk of preeclampsia. Epidemiology 2006, 17(4):428.

90. Glazer NL, Hendrickson AF, Schellenbaum GD, Mueller BA: Weight change and the risk of gestational diabetes in obese women. Epidemiology 2004, 15(6):733.

91. Gavard JA, Artal R: Effect of exercise on pregnancy outcome. Clinical Obstetrics and Gynecology 2008, 51(2):467.

92. Birdsall KM, Vyas S, Khazaezadeh N, Oteng Ntim E: Maternal obesity: a review of interventions. International journal of clinical practice 2009, 63(3):494-507.

93. Galtier F, Raingeard I, Renard E, Boulot P, Bringer J: Optimizing the outcome of pregnancy in obese women: from pregestational to longterm management. Diabetes \& metabolism 2008, 34(1):19-25.

94. Fortner RT, Pekow PS, Whitcomb BW, Sievert LL, Markenson G, ChasanTaber L: Physical Activity and Hypertensive Disorders of Pregnancy among Hispanic Women. Medicine \& Science in Sports \& Exercise 2011, 43(4):639.

95. Martin CL, Brunner Huber LR: Physical Activity and Hypertensive Complications During Pregnancy: Findings from 2004 to 2006 North Carolina Pregnancy Risk Assessment Monitoring System. Birth 2010, 37(3):202-210.

96. Rudra CB, Williams MA, Lee I: Perceived exertion during prepregnancy physical activity and preeclampsia risk. Medicine \& Science in Sports \& Exercise 2005, 37(11):1836.

97. Rudra CB, Sorensen TK, Luthy DA, Williams MA: A prospective analysis of recreational physical activity and preeclampsia risk. Medicine \& Science in Sports \& Exercise 2008, 40(9):1581.

98. Saftlas AF, Logsden-Sackett N, Wang W, Woolson R, Bracken MB: Work, leisure-time physical activity, and risk of preeclampsia and gestational hypertension. American journal of epidemiology 2004, 160(8):758.

99. Sorensen TK, Williams MA, Lee I: Recreational physical activity during pregnancy and risk of preeclampsia. Hypertension 2003, 41(6):1273.

100. Dempsey JC, Butler CL, Sorensen TK, Lee I: A case-control study of maternal recreational physical activity and risk of gestational diabetes mellitus* 1. Diabetes research and clinical practice 2004, 66(2):203-215.

101. Dempsey JC, Sorensen TK, Williams MA, Lee I: Prospective study of gestational diabetes mellitus risk in relation to maternal recreational physical activity before and during pregnancy. American journal of epidemiology 2004, 159(7):663. 
102. Oken E, Ning Y, Rifas-Shiman SL, Radesky JS, Rich-Edwards JW, Gillman MW: Associations of physical activity and inactivity before and during pregnancy with glucose tolerance. Obstetrics and gynecology 2006, 108(5):1200.

103. Rudra CB, Williams MA, Lee I: Perceived exertion in physical activity and risk of gestational diabetes mellitus. Epidemiology 2006, 17(1):31.

104. Tobias DK, Zhang C, van Dam RM, Bowers K, Hu FB: Physical Activity Before and During Pregnancy and Risk of Gestational Diabetes Mellitus. Diabetes Care 2011, 34(1):223.

105. Zhang C, Solomon CG, Manson JAE, Hu FB: A prospective study of pregravid physical activity and sedentary behaviors in relation to the risk for gestational diabetes mellitus. Archives of internal medicine 2006 166(5):543.

106. Kinnunen TI, Pasanen M, Aittasalo M, Fogelholm M, Weiderpass E, Luoto R Reducing postpartum weight retention - a pilot trial in primary health care. Nutrition Journal 2007, 6(1):21

107. Amorim Adegboye AR, Linne YM, Lourenco PMC: Diet or exercise, or both, for weight reduction in women after childbirth. 2007, 4, status and date: Edited (no change to conclusions).

108. Black MM, Hager ER, Le K, Anliker J, Arteaga SS, DiClemente C, Gittelsohn J, Magder L, Papas M, Snitker S: Challenge! Health Promotion/Obesity Prevention Mentorship Model Among Urban, Black Adolescents. Pediatrics 2010, 126(2):280.

109. Eiben G, Lissner L: Health Hunters-an intervention to prevent overweight and obesity in young high-risk women. International journal of obesity 2005, 30(4):691-696.

110. Faucher MA, Mobley J: A Community Intervention on Portion Control Aimed at Weight Loss in Low-Income Mexican American Women. Journal of Midwifery \& Women's Health 2010, 55(1):60-64.

111. Gokee LaRose J, Tate DF, Gorin AA, Wing RR: Preventing Weight Gain in Young Adults:: A Randomized Controlled Pilot Study. American journal of preventive medicine 2010.

112. Ostbye T, Krause KM, Lovelady CA, Morey MC, Bastian LA, Peterson BL, Swamy GK, Brouwer RJN, McBride CM: Active Mothers Postpartum:: A Randomized Controlled Weight-Loss Intervention Trial. American journal of preventive medicine 2009, 37(3):173-180.

113. Chang MW, Nitzke S, Brown R: Design and Outcomes of a Mothers In Motion Behavioral Intervention Pilot Study. Journal of Nutrition Education and Behavior 2010, 42(3S):11-21.

114. Harvey-Berino J, West D, Krukowski R, Prewitt E, VanBiervliet A, Ashikaga T, Skelly J: Internet delivered behavioral obesity treatment. Preventive medicine 2010.

115. Mediano MFF, Barbosa JSO, Moura AS, Willett WC, Sichieri R: A randomized clinical trial of home-based exercise combined with a slight caloric restriction on obesity prevention among women. Preventive medicine 2010.

116. Rock CL, Flatt SW, Sherwood NE, Karanja N, Pakiz B, Thomson CA: Effect of a Free Prepared Meal and Incentivized Weight Loss Program on Weight Loss and Weight Loss Maintenance in Obese and Overweight Women. JAMA: The Journal of the American Medical Association 2010, 304(16):1803.

117. Hall J, Solehdin F: Folic acid for the prevention of congenital anomalies. European journal of pediatrics 1998, 157(6):445-450.

118. Prevention of neural tube defects: results of the Medical Research Council Vitamin Study. MRC Vitamin Study Research Group. Lancet 1991, 338(760):131-137.

119. Kirke PN, Daly LE, Elwood JH: A randomised trial of low dose folic acid to prevent neural tube defects. The Irish Vitamin Study Group. British Medical Journal 1992, 67(12):1442.

120. Laurence KM, James N, Miller MH, Tennant GB, Campbell H: Double-blind randomised controlled trial of folate treatment before conception to prevent recurrence of neural-tube defects. British medical journal (Clinical research ed) 1981, 282(6275):1509.

121. Suarez L, Hendricks KA, Cooper SP, Sweeney AM, Hardy RJ, Larsen RD: Neural tube defects among Mexican Americans living on the US-Mexico border: effects of folic acid and dietary folate. American journal of epidemiology 2000, 152(11):1017-1023.

122. Vergel RG, Sanchez LR, Heredero BL, Rodriguez PL, Martinez AJ: Primary prevention of neural tube defects with folic acid supplementation: Cuban experience. Prenatal diagnosis 1990, 10(3):149-152.

123. Botto LD, Olney RS, Erickson JD: Vitamin supplements and the risk for congenital anomalies other than neural tube defects. John Wiley \& Sons; 2004, 12-21.
124. Johnson KJ, Alexander BH, Doody MM, Sigurdson AJ, Linet MS, Spector LG, Hoffbeck RW, Simon SL, Weinstock RM, Ross JA: Childhood cancer in the offspring born in 1921-1984 to US radiologic technologists. British journal of cancer 2008, 99(3):545-550.

125. Goh Yl, Bollano E, Einarson TR, Koren G: Prenatal multivitamin supplementation and rates of congenital anomalies: a meta-analysis. J Obstet Gynaecol Can 2006, 28(8):680-689.

126. Badovinac RL, Werler MM, Williams PL, Kelsey KT, Hayes C: Folic acidcontaining supplement consumption during pregnancy and risk for oral clefts: A meta analysis. Birth Defects Research Part A: Clinical and Molecular Teratology 2007, 79(1):8-15.

127. Suarez L, Hendricks KA, Cooper SP, Sweeney AM, Hardy RJ, Larsen RD: Neural tube defects among Mexican Americans living on the US-Mexico border: effects of folic acid and dietary folate. American journal of epidemiology 2000, 152(11):1017.

128. Berry RJ, Li Z, Erickson JD, Li S, Moore CA, Wang H, Mulinare J, Zhao P, Wong LYC, Gindler J: Prevention of neural-tube defects with folic acid in China. New England Journal of Medicine 1999, 341(20):1485.

129. Bower C, Stanley FJ: Periconceptional vitamin supplementation and neural tube defects; evidence from a case-control study in Western Australia and a review of recent publications. Journal of Epidemiology and Community Health 1992, 46(2):157.

130. Ulrich M, Kristoffersen K, Rolschau J, Grinsted P, Schaumburg E, Foged N: The influence of folic acid supplement on the outcome of pregnancies in the county of Funen in Denmark. Part II. Congenital anomalies. A randomised study. Eur J Obstet Gynecol Reprod Biol 1999, 87(2):111-113, discussion 103-114.

131. Central Technical Co-ordinating Unit, ICMRCentral Technical Co-ordinating Unit I: Multicentric study of efficacy of periconceptional folic acid containing vitamin supplementation in prevention of open neural tube defects from India. Indian J Med Res 2000, 112:206-211.

132. Smithells RW, Sheppard S, Schorah CJ, Seller MJ, Nevin NC, Harris R, Read AP, Fielding DW: Apparent prevention of neural tube defects by periconceptional vitamin supplementation. Archives of disease in childhood 1981, 56(12):911.

133. Chen G, Song X, Ji Y, Zhang L, Pei L, Chen J, Liu J, Li C, Zheng X: Prevention of NTDs with periconceptional multivitamin supplementation containing folic acid in China. Birth Defects Research Part A Clinical and Molecular Teratology 2008, 82(8):592-596.

134. Czeizel AE: Reduction of urinary tract and cardiovascular defects by periconceptional multivitamin supplementation. American Journal of Medical Genetics Part A 1996, 62(2):179-183.

135. Czeizel $A E$, Dobó $M$, Vargha P: Hungarian cohort controlled trial of periconceptional multivitamin supplementation shows a reduction in certain congenital abnormalities. Birth Defects Research Part A Clinical and Molecular Teratology 2004, 70(11):853-861.

136. Mulinare J, Cordero JF, Erickson JD, Berry RJ: Periconceptional use of multivitamins and the occurrence of neural tube defects. JAMA 1988, 260(21):3141.

137. Shaw GM, Schaffer D, Velie EM, Morland K, Harris JA: Periconceptional vitamin use, dietary folate, and the occurrence of neural tube defects. Epidemiology 1995, 6(3):219-226.

138. Werler MM, Shapiro S, Mitchell AA: Periconceptional folic acid exposure and risk of occurrent neural tube defects. JAMA 1993, 269(10):1257.

139. Bower C, Miller M, Payne J, Serna P: Folate intake and the primary prevention of non neural birth defects. Australian and New Zealand Journal of Public Health 2006, 30(3):258-261.

140. Czeizel AE, Timar L, Sarkozi A: Dose-dependent effect of folic acid on the prevention of orofacial clefts. Pediatrics 1999, 104(6):e66.

141. Hayes C, Werter MM, Willett WC, Mitchell AA: Case-control study of periconceptional folic acid supplementation and oral clefts. American journal of epidemiology 1996, 143(12):1229.

142. Johnson $C Y$, Little J: Folate intake, markers of folate status and oral clefts: is the evidence converging? International journal of epidemiology 2008, 37(5):1041.

143. Itikala PR, Watkins ML, Mulinare J, Moore CA, Liu Y: Maternal multivitamin use and orofacial clefts in offspring. Teratology 2001, 63(2):79-86.

144. Van Beynum IM, Kapusta L, Bakker MK, Den Heijer M, Blom HJ, de Walle HEK: Protective effect of periconceptional folic acid supplements on the risk of congenital heart defects: a registry-based case-control study in the northern Netherlands. European heart journal 2009. 
145. Scanlon KS, Ferencz C, Loffredo CA, Wilson PD, Correa-Villaseñor A, Khoury MJ, Willett WC: Preconceptional folate intake and malformations of the cardiac outflow tract. Epidemiology 1998, 9(1):95.

146. Botto LD, Khoury MJ, Mulinare J, Erickson JD: Periconceptional multivitamin use and the occurrence of conotruncal heart defects: results from a population-based, case-control study. Pediatrics 1996, 98(5):911.

147. Li DK, Daling JR, Mueller BA, Hickok DE, Fantel AG, Weiss NS: Periconceptional multivitamin use in relation to the risk of congenital urinary tract anomalies. Epidemiology 1995, 6(3):212.

148. Yang Q, Khoury MJ, Olney RS, Mulinare J: Does periconceptional multivitamin use reduce the risk for limb deficiency in offspring? Epidemiology 1997, 8(2):157-161.

149. Bitsko RH, Reefhuis J, Romitti PA, Moore CA, Honein MA: Periconceptional consumption of vitamins containing folic acid and risk for multiple congenital anomalies. American Journal of Medical Genetics Part A 2007 143(20):2397-2405

150. Czeizel $A E$, Medveczky E: Periconceptional multivitamin supplementation and multimalformed offspring. Obstetrics \& Gynecology 2003, 102(6):1255.

151. Khoury MJ, Shaw GM, Moore CA, Lammer EJ, Mulinare J: Does periconceptional multivitamin use reduce the risk of neural tube defects associated with other birth defects? Data from two population-based casecontrol studies. American Journal of Medical Genetics Part A 1996, 61(1):30-36.

152. Shaw GM, Croen LA, Todoroff K, Tolarova MM: Periconceptional intake of vitamin supplements and risk of multiple congenital anomalies. American journal of medical genetics 2000, 93(3):188-193.

153. Catov JM, Bodnar LM, Ness RB, Markovic N, Roberts JM: Association of periconceptional multivitamin use and risk of preterm or small-forgestational-age births. American journal of epidemiology 2007, 166(3):296.

154. Czeizel AE, Dudas I, Metneki J: Pregnancy outcomes in a randomised controlled trial of periconceptional multivitamin supplementation. Archives of Gynecology and Obstetrics 1994, 255(3):131-139.

155. Bodnar LM, Tang G, Ness RB, Harger G, Roberts JM: Periconceptional multivitamin use reduces the risk of preeclampsia. American journal of epidemiology 2006, 164(5):470.

156. Catov JM, Nohr EA, Bodnar LM, Knudson VK, Olsen SF, Olsen J: Association of periconceptional multivitamin use with reduced risk of preeclampsia among normal-weight women in the Danish National Birth Cohort. American journal of epidemiology 2009, 169(11):1304.

157. Calvo EB, Biglieri A: Impact of folic acid fortification on women nutritional status and on the prevalence of neural tube defects. Archivos argentinos de pediatría 2008, 106:492-498.

158. Mersereau P, Kilker K, Carter H, Fassett E, Williams J, Flores A, Prue C, Williams L, Mai C, Mulinare J: Spina bifida and anencephaly before and after folic acid mandate-United States, 1995-1996 and 1999-2000. Morbidity and Mortality Weekly Report 2004, 53(17):362-365.

159. De Wals $P$, Rusen ID, Lee NS, Morin P, Niyonsenga T: Trend in prevalence of neural tube defects in Quebec. Birth Defects Research Part A: Clinical and Molecular Teratology 2003, 67(11):919-923.

160. Gucciardi E, Pietrusiak MA, Reynolds DL, Rouleau J: Incidence of neural tube defects in Ontario, 1986-1999. Canadian Medical Association Journal 2002, 167(3):237

161. Honein MA, Paulozzi LJ, Mathews TJ, Erickson JD, Wong LYC: Impact of folic acid fortification of the US food supply on the occurrence of neural tube defects. Jama 2001, 285(23):2981.

162. Liu S, West R, Randell E, Longerich L, O'Connor KS, Scott H, Crowley M, Lam A, Prabhakaran V, McCourt C: A comprehensive evaluation of food fortification with folic acid for the primary prevention of neural tube defects. BMC Pregnancy and Childbirth 2004, 4(1):20.

163. López Camelo JS, Orioli IM, Dutra MG, Nazer Herrera J, Rivera N, Ojeda ME, Canessa A, Wettig E, Fontannaz AM, Mellado C: Reduction of birth prevalence rates of neural tube defects after folic acid fortification in Chile. American Journal of Medical Genetics Part A 2005, 135(2):120-125.

164. Persad VL, Van den Hof MC, Dube JM, Zimmer P: Incidence of open neural tube defects in Nova Scotia after folic acid fortification. Canadian Medical Association Journal 2002, 167(3):241.

165. Ray JG, Meier C, Vermeulen MJ, Boss S, Wyatt PR, Cole DEC: Association of neural tube defects and folic acid food fortification in Canada. The Lancet 2002, 360(9350):2047-2048.

166. Sayed AR, Bourne D, Pattinson R, Nixon J, Henderson B: Decline in the prevalence of neural tube defects following folic acid fortification and its cost benefit in South Africa. Birth Defects Research Part A: Clinical and Molecular Teratology 2008, 82(4):211-216.

167. Simmons CJ, Mosley BS, Fulton Bond CA, Hobbs CA: Birth defects in Arkansas: Is folic acid fortification making a difference? Birth Defects Research Part A: Clinical and Molecular Teratology 2004, 70(9):559-564.

168. Williams LJ, Mai $C T$, Edmonds LD, Shaw GM, Kirby RS, Hobbs CA, Sever LE, Miller LA, Meaney FJ, Levitt M: Prevalence of spina bifida and anencephaly during the transition to mandatory folic acid fortification in the United States. Teratology 2002, 66(1):33-39.

169. Williams LJ, Rasmussen SA, Flores A, Kirby RS, Edmonds LD: Decline in the prevalence of spina bifida and anencephaly by race/ethnicity: 19952002. Pediatrics 2005, 116(3):580.

170. Li Z, Gindler J, Wang H, Berry RJ, Li S, Correa A, Zheng J, Erickson JD, Wang Y: Folic acid supplements during early pregnancy and likelihood of multiple births: a population-based cohort study. The Lancet 2003, 361(9355):380-384.

171. Vollset SE, Gjessing HK, Tandberg A, Rønning T, Irgens LM, Baste V, Nilsen RM, Daltveit AK: Folate supplementation and twin pregnancies. Epidemiology 2005, 16(2):201.

172. Lawrence JM, Watkins ML, Chiu V, Erickson JD, Petitti DB: Food fortification with folic acid and rate of multiple births, 1994-2000. Birth Defects Research Part A: Clinical and Molecular Teratology 2004, 70(12):948-952.

173. Shaw GM, Carmichael SL, Nelson V, Selvin S, Schaffer DM: Food fortification with folic acid and twinning among California infants. American Journal of Medical Genetics Part A 2003, 119(2):137-140.

174. Signore C, Mills JL, Cox C, Trumble AC: Effects of folic acid fortification on twin gestation rates. Obstetrics \& Gynecology 2005, 105(4):757.

175. Chevrier C, Perret C, Bahuau M, Zhu H, Nelva A, Herman C, Francannet C, Robert Gnansia E, Finnell RH, Cordier S: Fetal and maternal MTHFR C677T genotype, maternal folate intake and the risk of nonsyndromic oral clefts. American Journal of Medical Genetics Part A 2007, 143(3):248-257.

176. Little J, Gilmour M, Mossey PA, FitzPatrick D, Cardy A, Clayton-Smith J, Fryer AE: Folate and Clefts of the Lip and Palate-A UK-Based CaseControl Study: Part I: Dietary and Supplemental Folate. The Cleft PalateCraniofacial Journal 2008, 45(4):420-427.

177. Shaw GM, Carmichael SL, Laurent C, Rasmussen SA: Maternal nutrient intakes and risk of orofacial clefts. Epidemiology 2006, 17(3):285.

178. van Rooij I, Swinkels DW, Blom HJ, Merkus H, Steegers-Theunissen RPM: Vitamin and homocysteine status of mothers and infants and the risk of nonsyndromic orofacial clefts* 1 . American Journal of Obstetrics and Gynecology 2003, 189(4):1155-1160.

179. Wilcox AJ, Lie RT, Solvoll K, Taylor J, McConnaughey DR, Åbyholm F, Vindenes $\mathrm{H}$, Vollset SE, Drevon CA: Folic acid supplements and risk of facial clefts: national population based case-control study. BMJ 2007, 334(7591):464

180. De Walle HEK, De Jong Van Den Berg LTW: Insufficient folic acid intake in the Netherlands: what about the future? Teratology 2002, 66(1):40-43.

181. Kannan S, Menotti E, Scherer HK, Dickinson J, Larson K: Folic acid and the prevention of neural tube defects: A survey of awareness among Latina women of childbearing age residing in southeast Michigan. Health promotion practice 2007, 8(1):60.

182. Kari JA, Bardisi ES, Baitalmal RM, Ageely GA: Folic acid awareness among female college students: neural tube defects prevention. Saudi Med J 2008, 29(12):1749-1751.

183. Sillender M, Pring DW: How effective was the Health Education Authority s folic acid campaign? Journal of Obstetrics and Gynaecology 2000, 20(3):271-276.

184. Der Pal de Bruin V: The Dutch 'Folic Acid Campaign'-have the goals been achieved? Paediatric and Perinatal Epidemiology 2000, 14(2):111-117.

185. Chan A, Pickering J, Haan EA, Netting M, Burford A, Johnson A, Keane RJ: " Folate before pregnancy": the impact on women and health professionals of a population-based health promotion campaign in South Australia. Obstetrical \& Gynecological Survey 2002, 57(1):8.

186. Pastuszak A, Bhatia D, Okotore B, Koren G: Preconception counseling and women's compliance with folic acid supplementation. Canadian Family Physician 1999, 45(2053)

187. Stevenson RE, Allen WP, Pai GS, Best R, Seaver LH, Dean J, Thompson S: Decline in prevalence of neural tube defects in a high-risk region of the United States. Pediatrics 2000, 106(4):677.

188. Robbins JM, Cleves MA, Collins HB, Andrews N, Smith LN, Hobbs CA: Randomized trial of a physician-based intervention to increase the use 
of folic acid supplements among women. American Journal of Obstetrics and Gynecology 2005, 192(4):1126-1132.

189. Watson MJ, Watson LF, Bell RJ, Halliday JL, Burford N, Brennecke SP: A randomized community intervention trial to increase awareness and knowledge of the role of periconceptional folate in women of childbearing age. Health Expect 1999, 2(4):255-265.

190. Watson M, Watson L, Bell R, Halliday J: The increasing knowledge of the role of periconceptional folate in Victorian women of child-bearing age: follow-up of a randomised community intervention trial. Aust N Z J Public Health 2001, 25(5):389-395.

191. Chacko MR, Anding R, Kozinetz CA, Grover JL, Smith PB: Neural tube defects: knowledge and preconceptional prevention practices in minority young women. Pediatrics 2003, 112(3):536.

192. Hauser KW, Lilly CM, Frías JL: Florida health care providers' knowledge of folic acid for the prevention of neural tube defects. Southern medical journal 2004, 97(5):437.

193. Watkins ML, Brustrom J, Schulman J: Effectiveness of a free folic acid supplement program in family planning clinics. Birth Defects Research Clinical and Molecular Teratology 2004, 70(6):403-407.

194. Lawrence JM, Watkins ML, Ershoff D, Petitti DB, Chiu V, Postlethwaite D, Erickson JD: Design and evaluation of interventions promoting periconceptional multivitamin use. American Journal of Preventive Medicine 2003, 25(1):17-24.

195. Egen V, Hasford J: Prevention of neural tube defects: effect of an intervention aimed at implementing the official recommendations. Sozial-und Präventivmedizin/Social and Preventive Medicine 2003, 48(1):24-32.

196. Mullenix A: Reaching Women and Health Care Providers with Women's Wellness Messages. NC Med J 2009, 70(5).

197. Baro L, Martinez-Ferez A, Rodriguez C, Valero A, Fonolla J, Lucena A, Jimenez J, Boza JJ, Lopez-Huertas E: The administration of a multivitamin/ mineral fortified dairy product improves folate status and reduces plasma homocysteine concentration in women of reproductive age. International journal for vitamin and nutrition research 2004, 74(3):234-240.

198. de Weerd S, Thomas CMG, Cikot RJLM, Steegers-Theunissen RPM, de Boo TM, Steegers EAP: Preconception counseling improves folate status of women planning pregnancy. Obstetrics \& Gynecology 2002, 99(1):45.

199. Muggli EE, Halliday JL: Folic acid and risk of twinning: a systematic review of the recent literature, July 1994 to July 2006. Medical Journal of Australia 2007, 186(5):243.

200. Shaw GM, O'Malley CD, Wasserman CR, Tolarova MM, Lammer EJ: Maternal periconceptional use of multivitamins and reduced risk for conotruncal heart defects and limb deficiencies among offspring. American journal of medical genetics 1995, 59(4):536-545.

201. Wang Y, Jun PEIL, Ming SX, Gong C, Ying ZX: Impact of Periconceptional Multi-micronutrient Supplementation on Gestation: A Population-based Study. Biomed Environ Sci 2013, 26(1):23-31.

202. Ronnenberg AG, Wood RJ, Wang X, Xing H, Chen C, Chen D, Guang W, Huang A, Wang L, Xu X: Preconception hemoglobin and ferritin concentrations are associated with pregnancy outcome in a prospective cohort of Chinese women. Journal of Nutrition 2004, 134(10):2586.

203. Imdad A, Yakoob MY, Bhutta Z: Effect of breastfeeding promotion interventions on breastfeeding rates, with special focus on developing countries. BMC Public Health 2011, 11(Suppl 3):S24.

204. Peña-Rosas JP, V F: Effects and safety of preventive oral iron or iron+folic acid supplementation for women during pregnancy. 2009.

205. Berger J, T H, Cavalli-Sforza T, Smitasiri S, Khan NC, Milani S: Community mobilization and social marketing to promote weekly iron-folic acid supplementation in women of reproductive age in Vietnam: impact on anemia and iron status. 2005.

206. Angeles-Agdeppa I, P L, Ramos AC, Etorma UM, Cavalli-Sforza T, Milani S: Government-Industry Partnership in Weekly Iron-Folic Acid Supplementation for Women of Reproductive Age in the Philippines. 2005.

207. Khambalia AZ, O'Connor DL, Macarthur C, Dupuis A, Zlotkin SH: Periconceptional iron supplementation does not reduce anemia or improve iron status among pregnant women in rural Bangladesh. The American journal of clinical nutrition 2009, 90(5):1295-1302.

208. Casey GJ, J D, Phuc TQ, Tinh TT, Tho DH: Long-term weekly iron-folic acid and de-worming is associated with stabilised haemoglobin and increasing iron stores in non-pregnant women in Vietnam. 2010

209. Passerini L, C G, Biggs BA, Cong DT, Phu LB, Phuc TQ, Carone M, Montresor A: Increased birth weight associated with regular pre-pregnancy deworming and weekly iron-folic acid supplementation for Vietnamese women. 2012.

210. Vir SC, S N, Nigam AK, Jain R: Weekly iron and folic acid supplementation with counseling reduces anemia in adolescent girls. 2008.

211. Mendez MA, Monteiro CA, Popkin BM: Overweight exceeds underweight among women in most developing countries. American Journal of Clinical Nutrition 2005, 81(3):714.

212. Han YW: Oral Health and Adverse Pregnancy Outcomes-What's Next? Journal of Dental Research 2011, 90(3):289.

213. O'Brien TE, Ray JG, Chan WS: Maternal body mass index and the risk of preeclampsia: a systematic overview. Epidemiology 2003, 14(3):368.

214. Torloni MR, Betrán AP, Horta BL, Nakamura MU, Atallah AN, Moron AF, Valente O: Prepregnancy BMI and the risk of gestational diabetes: a systematic review of the literature with meta analysis. Obesity Reviews 2009, 10(2):194-203.

215. Poobalan AS, Aucott LS, Gurung T, Smith WCS, Bhattacharya S: Obesity as an independent risk factor for elective and emergency caesarean delivery in nulliparous women-systematic review and meta analysis of cohort studies. Obesity Reviews 2009, 10(1):28-35.

216. Nuthalapaty FS, Rouse DJ: The impact of obesity on obstetrical practice and outcome. Clinical obstetrics and gynecology 2004, 47(4):898.

217. WHO: Consultation on Antiretroviral Treatment for Prevention of HIV Transmission. Meeting Report. Geneva, Switzerland; 2009.

218. Vrebosch L, B S, Vansant: Maternal and neonatal outcome after laparoscopic adjustable gastric banding: a systematic. 2012

219. Cornel MC, Erickson JD: Comparison of national policies on periconceptional use of folic acid to prevent spina bifida and anencephaly (SBA). Teratology 1997, 55(2):134-137.

220. Bener A, Al Maadid MGA, Al-Bast DAE, Al-Marri S: Maternal knowledge, attitude and practice on folic acid intake among Arabian Qatari women. Reproductive Toxicology 2005, 21(1):21-25.

221. Brough L, Rees GA, Crawford MA, Dorman EK: Social and ethnic differences in folic acid use preconception and during early pregnancy in the UK: effect on maternal folate status. Journal of human nutrition and dietetics 2009, 22(2):100-107.

222. Coll O, Pisa S, Palacio M, Quintó L, Cararach V: Awareness of the use of folic acid to prevent neural tube defects in a Mediterranean area. European Journal of Obstetrics \& Gynecology and Reproductive Biology 2004, 115(2):173-177.

223. CDC: The importance of preconception care in the continuum of women's health care. Obstet Gynecol Clin North Am 2005, 106(3):665-666.

224. De Walle HE, Van der Pal KM: Periconceptional folic acid in The Netherlands in 1995. Socioeconomic differences. Journal of epidemiology and community health 1998, 52(12):826.

225. Howell SR, Barnett AG, Underwood MR: The use of pre-conceptional folic acid as an indicator of uptake of a health message amongst white and Bangladeshi women in Tower Hamlets, east London. Family Practice 2001, 18(3):300

226. Nawapun K, Phupong V: Awareness of the benefits of folic acid and prevalence of the use of folic acid supplements to prevent neural tube defects among Thai women. Archives of Gynecology and Obstetrics 2007, 276(1):53-57.

227. Tamim H, Harrison G, Atoui M, Mumtaz G, El-Kak F, Seoud M, Yunis K: Preconceptional folic acid supplement use in Lebanon. Public health nutrition 2009, 12(05):687-692.

228. Paudel P, W K, Silpakar SK: Awareness of periconceptional folic acid supplementation among Nepalese women of childbearing age: a crosssectional study. 2012.

229. Stockley L, Lund V: Use of folic acid supplements, particularly by lowincome and young women: a series of systematic reviews to inform public health policy in the UK. Public health nutrition 2008, 11(08):807-821.

230. Botto LD, Lisi A, Bower C, Canfield MA, Dattani N, De Vigan C, De Walle H, Erickson DJ, Halliday J, Irgens LM: Trends of selected malformations in relation to folic acid recommendations and fortification: an international assessment. Birth Defects Research Part A: Clinical and Molecular Teratology 2006, 76(10):693-705

231. Oakley GP: Folate deficiency is an"imminent health hazard" causing a worldwide birth defects epidemic. Birth Defects Research Part A Clinical and Molecular Teratology 2003, 67(11):903-904.

232. W NJ: Folic acid and the prevention of neural-tube defects. 2004. 
233. Locksmith GJ, Duff P: Preventing neural tube defects: the importance of periconceptional folic acid supplements. Obstetrics \& Gynecology 1998, 91(6):1027.

234. Kondo A, Kamihira O, Ozawa H: Neural tube defects: Prevalence, etiology and prevention. International Journal of Urology 2009, 16(1):49-57.

235. Holzgreve W, P K, Koletzko B: Adding folate to the contraceptive pill: a new concept for the prevention of neural tube defects.J Matern Fetal Neonata. 2012.

236. Van Thuy P, Berger J, Nakanishi Y, Khan NC, Lynch S, Dixon P: The use of NaFeEDTA-fortified fish sauce is an effective tool for controlling iron deficiency in women of childbearing age in rural Vietnam. The Journal of nutrition 2005, 135(11):2596-2601.

237. Sadighi J, Mohammad K, Sheikholeslam R, Amirkhani MA, Torabi P, Salehi F, Abdolahi Z: Anaemia control: lessons from the flour fortification programme. Public health 2009, 123(12):794-799.

238. Hotz C, Porcayo M, Onofre Gn, GarcÃa-Guerra A, Elliott T, Jankowski S, Greiner T: Efficacy of iron-fortified Ultra Rice in improving the iron status of women in Mexico. Food \& Nutrition Bulletin 2008, 29(2):140-149.

239. Blanco-Rojo R, Perez-Granados AM, Toxqui L, Gonzalez-Vizcayno C, Delgado MA, Vaquero MP: Efficacy of a microencapsulated iron pyrophosphate-fortified fruit juice: a randomised, double-blind, placebocontrolled study in Spanish iron-deficient women. British Journal of Nutrition 2011, 105(11):1652.

240. Biebinger R, Zimmermann MB, Al-Hooti SN, Al-Hamed N, Al-Salem E, Zafar T, Kabir Y, Petry N, Hurrell RF: Efficacy of wheat-based biscuits fortified with microcapsules containing ferrous sulfate and potassium iodate or a new hydrogen-reduced elemental iron: a randomised, double-blind, controlled trial in Kuwaiti women. British Journal of Nutrition 2009, 102(09):1362-1369.

241. Bhutta ZA, S R: Global nutrition epidemiology and trends. 2012.

242. Dean SV, Lassi ZS, Imam AM, Bhutta ZA: Preconception care: promoting reproductive planning. Reproductive Health 2014.

\section{Submit your next manuscript to BioMed Central and take full advantage of:}

- Convenient online submission

- Thorough peer review

- No space constraints or color figure charges

- Immediate publication on acceptance

- Inclusion in PubMed, CAS, Scopus and Google Scholar

- Research which is freely available for redistribution

Submit your manuscript at www.biomedcentral.com/submit
Biomed Central 